The scheme provides the psychiatric higher trainee with opportunities to develop negotiation skills with colleagues in a variety of disciplines. As might be expected, over-burdened local services are often initially sceptical about admitting patients to their few beds (especially since this group will often require intensive nursing input) when the staff have not had an opportunity to make a complete community assessment and information concerning prior history is sketchy. Having said this, we have found that the offender is often well known to local services, which may clarify the potential benefits accruing from admission.

In addition, there is a need to develop the ability to give a concise account of the patient's mental state and suggestions concerning disposal to solicitors either while pursuing them down corridors or in whispered communications in the magistrates' court between cases. Whether there are other settings in which this skill can be utilised is, however, debatable! On the other hand, we have found that participation in the scheme has been rewarding, both personally and professionally. The police officers and officers of the court with whom we have had dealings have been unfailingly helpful. All have appeared to be very receptive to the scheme and concerned that it should succeed.

The defendants who are seen are frequently charged with minor crimes and display symptoms of florid psychosis. Without psychiatric diversion the court has no options other than to return the person into the community or to remand him or her into custody. Given the time limitations of the court, unless psychiatric services are available in situ, the possibility of organising an urgent psychiatric opinion for the court would be almost non-existent.

As a training opportunity we believe the scheme is unusual, in that it teaches one to make rapid assessments which are sufficiently coherent so as to stand up to scrutiny by lawyers. In addition, the opportunity of diverting the mentally ill from custody towards appropriate psychiatric treatment is one we have found to be satisfying, in spite of any angst involved in the proceedings.

\section{Acknowledgements}

Our thanks to Dr R. V. Cope for her comments on an earlier draft of this manuscript.

\section{References}

HoME OfFice (1990) Report of Her Majesty's Chief Inspector of Prisons 1989. London: HMSO.

-1990) HMP Brixton: Report by HM Chief Inspector of Prisons. London: Home Office.

James, D. V. \& Hamilton, L. W. (1991) The Clerkenwell scheme: assessing efficacy and cost of a psychiatric liaison service to a magistrates' court. British Medical Journal. 303, 282-285.

Joseph, P. L. \& PotTer, M. (1990) Mentally disordered homeless offenders: diversion from custody. Health Trends, 22, 51-53.

\title{
A review of training in neuropsychiatry
}

\author{
A. NiCOL, Research Registrar; and J. BIRD, Consultant Neuropsychiatrist, \\ Burden Neurological Hospital, Stapleton, Bristol BS16 1QT
}

The boundary between neurology and psychiatry has never been sharply defined. It remains the case that a number of conditions (e.g. epilepsy, headinjury sequelae, dementia, and conversion hysteria) are seen by both neurologists and psychiatrists (Reynolds \& Trimble, 1989). Few neurologists would dispute that there may be a marked psychiatric element to the presentation of multiple sclerosis, and it has long been noticed that even unmedicated chronic schizophrenic patients sometimes exhibit abnormalities of movement and so-called "soft" neurological signs such as dysgraphia and clumsiness (Lishman, 1988). These and other conditions may all on occasion present to the neuropsychiatrist.
Neuropsychiatry has re-emerged in recent years as an apparently new speciality. Present post-graduate training in the UK is such that practising neuropsychiatrists may well never have held a neuropsychiatry training post, but instead cobbled together their own scheme of training through neurology, neurosurgery and psychiatry posts. Some may have held neuropsychiatry posts overseas. It would seem self-evident that some formal training in neuropsychiatry might be of benefit to the vast majority of practising psychiatrists, and essential to the neuropsychiatrist.

With this in mind, we attempted to establish how much neuropsychiatric training is available to 
psychiatric trainees in the UK, where it is offered and what it comprises.

\section{The study}

A questionnaire and brief explanatory letter were sent to each of the 26 co-ordinators of higher psychiatric training the UK. The questionnaire enquired specifically about the neuropsychiatry training posts available, and asked for details of regular and occasional sessional training in neuropsychiatry and experience in allied subjects. Opinions on the value of neuropsychiatry training were canvassed and further comments on the subject were invited.

Twenty fully-completed questionnaires were returned, and a further five letters were received containing relevant information. The one remaining co-ordinator was contacted by telephone.

\section{Findings}

It emerged that there are a total of five senior registrar neuropsychiatry posts in the UK, two of which are at the Maudsley, one each in Belfast and Keele, and a shared post (with liaison psychiatry) in Birmingham. There are three academic posts: a lecturer at the National Hospital, Queen Square, a senior tutor (honorary SR) in Belfast and a tutor (research registrar) in Bristol. One of the registrars in Keele spends six sessions per week in neuropsychiatry.

In addition to the above posts, regular sessional training was offered on nine rotations, chiefly in the form of out-patients attendance, and occasional experience in neuropsychiatry was available on 12 schemes.

Experience in allied subjects was widely available, although only 10 out of the 26 schemes could offer experience in physical rehabilitation, and only 15 in neuropsychology. Seventeen offered experience or training in basic brain science, 19 in clinical neurophysiology (EEG), and 19 in neuropsychopharmacology. Research in neuropsychiatry was offered by 19 of the schemes, and training in neurology was available on 20.

It appeared that eight schemes offered no more than occasional experience, while three afforded no training in neuropsychiatry bar experience in allied subjects. Only two rotations-Keele and the
Maudsley - offered more than one substantive post in neuropsychiatry.

Concerning the value of neuropsychiatry training, 16 co-ordinators were of the opinion that it should be available to all and nine that it should be available to some. None expressed the opinion that training in neuropsychiatry was unnecessary.

Eight further comments were made, all to the effect that neuropsychiatry was under-represented in psychiatric training, either locally or nationally.

\section{Comment}

The relative prominence of neurological and psychological paradigms of psychiatry has oscillated during the course of this century. Many psychiatrists would agree that, as far as aetiological hypotheses are concerned, the former currently holds ascendancy. Neuroscience has advanced greatly through recent developments in brain imaging of both structure and function, and other techniques. It seems highly probably that only further advancement in this area will lead to a fuller understanding and better treatment of the major psychiatric disorders.

This survey has demonstrated that there are only four full-time senior registrar posts in neuropsychiatry and two lectureships in the UK. A review of consultant NHS and academic posts carried out independently (Bird, J. M., in preparation) shows that there are 26 incumbents who would say that their principal work is in the field of neuropsychiatry. New posts have recently been established in three centres and others are planned. An increasing number of both general and child psychiatrists are taking up special interests in neuropsychiatry.

A neuropsychiatrist has been defined as "a psychiatrist who knows and cares where the brain is". Are training schemes in this country currently geared to producing an adequate supply of such practitioners? The evidence of this study would suggest not.

\section{References}

Lishman, A. (1988) Organic Psychiatry. 2nd ed. Oxford: Blackwells.

ReYNolds, E. H. \& Trimble, M. R. (eds) (1989) The Bridge between Neurology and Psychiatry. Edinburgh: Churchill Livingstone. 